\title{
Modified Graphene Sheet Stacks for Hydrogen Binding
}

\section{Peteris LESNICENOKS ${ }^{\mathbf{1}}{ }^{*}$, Janis ZEMITIS ${ }^{\mathbf{1}}$, Liga GRINBERGA ${ }^{\mathbf{1}}$, George CHIKVAIDZE ${ }^{\mathbf{1}}$, Janis KLEPERIS ${ }^{1}$, Marius URBONAVIČIUS ${ }^{2}$, Simona TUČKUTE ${ }^{2}$, Darius MILČIUS ${ }^{2}$}

\author{
${ }^{1}$ Institute of Solid State Physics, University of Latvia, 8 Kengaraga Str., Riga, LV-1068, Latvia \\ ${ }^{2}$ Lithuanian Energy Institute, Breslaujos str. 3, LT-44403 Kaunas, Lithuania \\ cross $^{\text {ref }}$ http://dx.doi.org/10.5755/j01.ms.23.1.13729
}

\section{Received 01 December 2015; accepted 05 February 2016}

\begin{abstract}
Graphene sheet stacks were obtained using electrochemical exfoliation method. The morphology, distribution of elements and structure of the obtained samples were investigated using scanning electron microscopy, energy dispersive spectroscopy, Raman spectroscopy and Brunauer-Emmett-Teller methods. The graphene sheet stacks mostly have been formed with open stack structures having surface area of $124 \mathrm{~m}^{2} / \mathrm{g}$. Mg intercalation in graphene sheet structures was obtained adding $\mathrm{MgCl}_{2}$ during exfoliation process. Hydrogen desorption were measured in the temperature range $100-473 \mathrm{~K}$ at the pressure 2 bar reaching maximal desorbed hydrogen amount of $0.12-0.43 \mathrm{wt} . \%$.

Keywords: hydrogen storage, graphene, exfoliation, multi-sheet stacks.
\end{abstract}

\section{INTRODUCTION}

The interest in porous materials with high surface area for hydrogen storage having high hydrogen content, low weight, small volume and close to room temperature adsorption/desorption kinetics are still actual. Graphene having many extraordinary properties is considered as one of the most promising hydrogen storing material [1].

Usually graphene nanostructures show low $\mathrm{H}_{2}$ adsorption capacity at ambient conditions. Although Patchkovskii et al. [2] computational data shows that $\mathrm{H}_{2}$ adsorption capacities on graphene can approach U.S. Department of Energy goals of values of $6.5 \mathrm{wt} . \%$ and $62 \mathrm{~kg} / \mathrm{m}^{3}$ volumetric density of absorbed $\mathrm{H}_{2}$ at room temperature, experimental data up to now are substantially lower. Ghosh et al. [3] reports that $\mathrm{H}_{2}$ adsorption on few layer graphene samples prepared by the exfoliation method reached $\mathrm{H}_{2}$ uptake value of $1.7 \mathrm{wt} . \%$ at $77 \mathrm{~K}$ and $1 \mathrm{~atm}$. It has been found [4] that adsorption of $\mathrm{H}_{2}$ is directly proportional to the surface area of the sample, and adsorption of 3 wt.\% was achieved at $298 \mathrm{~K}$ and $100 \mathrm{~atm}$. There are no studies on hydrogen adsorption on graphene at low pressures and temperatures close to room temperature.

To achieve higher hydrogen storing capacities the chemical doping of graphitic material with catalysts are considered. A large number of scientific papers report on theoretical calculations of the modified graphene structures doped with alkali ( $\mathrm{Li}, \mathrm{Na}, \mathrm{K})$, alkaline earth $(\mathrm{Mg}, \mathrm{Ca})$, noble $(\mathrm{Pd}, \mathrm{Pt})$ and other metals [5-7]. The aim of doping graphene structures is to increase the binding energy thus increasing adsorbed amount of $\mathrm{H}_{2}$ due to the hybridization of $\mathrm{H}_{2}$ orbitals with transition metal orbitals and electric field caused polarisation of $\mathrm{H}_{2}$ molecules [8].

In our research graphene sheet stacks are obtained by electrochemical exfoliation method. Hydrogen desorption in as obtained and intercalated with $\mathrm{Mg}$ ions graphene multi-

\footnotetext{
${ }^{*}$ Corresponding author. Tel.: +371 29100445; fax: +371-67132778

E-mail address: peteris.lesnicenoks@gmail.com (P. Lesnicenoks)
}

stack sheets is investigated with structural, morphological, spectroscopic and thermal desorption methods.

\section{EXPERIMENTAL}

Graphene sheet stacks (GSS) were obtained by electrochemical exfoliation method using 2 electrode electrochemical cell. Graphite industrial waste rod was used as a working electrode, $\mathrm{Pt}$ foil served as a reference electrode. Both electrodes were immersed in $1 \mathrm{~mol} / 1 \mathrm{H}_{2} \mathrm{SO}_{4}$ electrolyte.

Electrodes were pre-treated by applying $+2 \mathrm{~V}$ voltage for 60 seconds. Exfoliation process started by applying $-10 \mathrm{~V}$ for 3 seconds and $+10 \mathrm{~V}$ for 5 seconds repeating this voltage sequence for 3 hours. The gained suspension was filtered by vacuum filtration method followed by ultrasonic bath treatment procedure in deionised water at $24 \mathrm{kHz}$ for 3 hours. After sedimentation the obtained sample particles were collected and dried. Part of powder was annealed in $\mathrm{Ar} / \mathrm{H}_{2}(95: 5)$ gas flow at $600{ }^{\circ} \mathrm{C}$ for 4 hours.

Intercalation of $\mathrm{Mg}$ ions for several samples were performed during exfoliation process by adding $0.01 \mathrm{~mol} / \mathrm{l}$ $\mathrm{MgCl}$ in electrolyte followed (identical sample preparation steps described above).

Scanning electron microscope (SEM) images of raw, reduced and intercalated samples were obtained by Hitachi S-400N with following elemental mapping by energy dispersive spectrometer (EDS) and Lyra Tescan.

Confocal inVia Raman Microscope (Renishaw) was used to get powder sample spectra in the region $200-3500 \mathrm{~cm}^{-1}$ (excitation wavelength $514 \mathrm{~nm}$, beam diameter $1 \mu \mathrm{m}$, power $35 \mathrm{~mW}$ and Raman spectra accumulation time $10 \mathrm{sec} / \mathrm{scan}, 5$ scans) (Fig. 4); $50 \mathrm{~mW}$ $200 \mathrm{~ns}$ pulse laser $532 \mathrm{~nm}, 20 \mu \mathrm{m},(600 \mathrm{~s} / \mathrm{scan}) / 50 \mathrm{~cm}^{-1}$, 2 scans (Fig. 5). Surface area was determined by BrunauerEmmett-Teller (BET) method using nitrogen gas sorption measurements at $77 \mathrm{~K}$ with Nova 1200 E-Series, 
Quantachrome Instruments at Latvian Wood Chemistry institute.

All samples were out gassed before hydrogen desorption measurements for $2 \mathrm{~h}$ at $493 \mathrm{~K}$. Amount of desorbed hydrogen were measured using volumetric method in the temperature range $100-473 \mathrm{~K}$ at the pressure 2 bar. The composition of desorbed gases were controlled by Mass Spectrometer RGA - 100 .

\section{RESULTS}

The morphology of all prepared samples (as prepared, reduced, and intercalated with $\mathrm{Mg}$ ) was studied by SEM (Fig. 1-Fig. 3, respectively). The obtained SEM images show agglomerated, stacked structures reminding puff pastry with deep voids between stacked sheets (Fig. 1), where few layer sheets can be distinguished with dimensions $15-25 \mu \mathrm{m}$ (Fig. 2) and thickness 66 to $112 \mathrm{~nm}$ (Fig. 3). Distinctly flaky structure promises a large specific surface area and many "pockets" where to accumulate hydrogen during adsorption process.

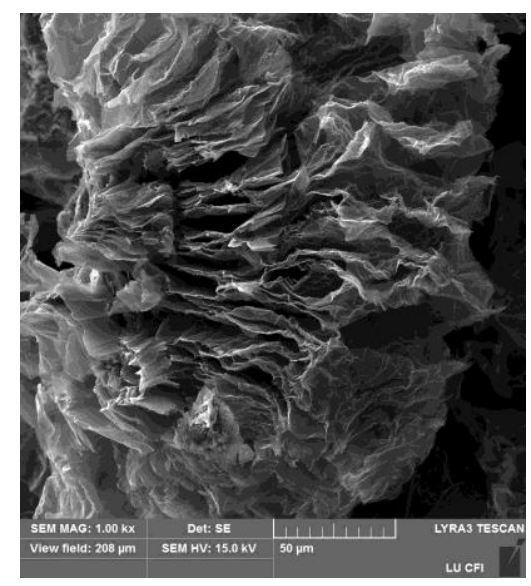

Fig. 1. SEM picture of raw GSS sample

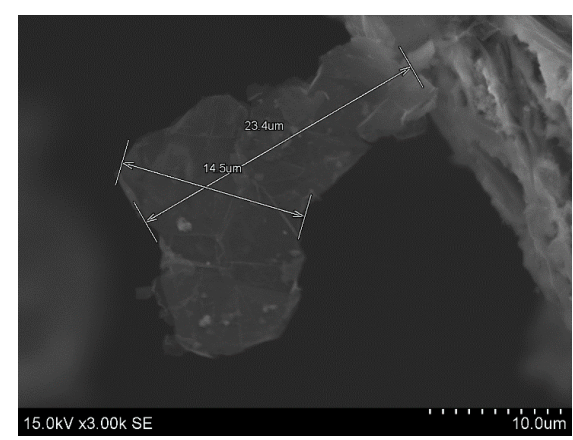

Fig. 2. SEM picture of reduced GSS sample

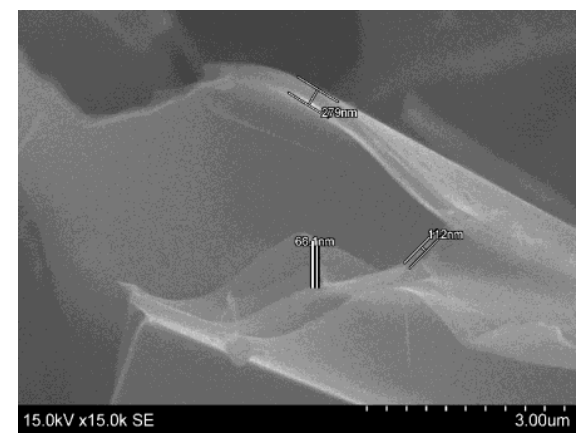

Fig. 3. Mg intercalated GSS
Ability to open the graphite carbon layer galleries by chemical means enables the preparation of bulk quantities of single or few-layer graphene by combining intercalation with dispersion in a polar solvent [9]. The redox-driven intercalation of ions and cations in Fan der Waals layered solids involve host-guest charge transfer, which facilitates opening of the outermost galleries [10]. The process is initiated by activation of the outermost host layers mostly by acid-base reactions and the guest molecule activity must exceed a threshold value for bulk intercalation to occur.

EDS mapping of Mg-intercalated sample showed that $\mathrm{Mg}$ together with some impurity elements (Table 1) are mostly located on the outer surfaces of sheet stack. Occurrence of impurities is caused by use of waste graphite and cannot be avoided by heat treatment and degassing of samples.

Table 1. Element analysis (EDS) of Mg GSS

\begin{tabular}{|c|c|c|}
\hline Element & norm.at.\% & Error in \% \\
\hline Carbon & 34.06 & 9.5 \\
\hline Oxygen & 55.97 & 39.9 \\
\hline Sulfur & 0.24 & 0.05 \\
\hline Magnesium & 0.15 & 0.044 \\
\hline
\end{tabular}

BET analysis confirms that the surface area of raw (non-reduced) sample and intercalated sample decreases from $124 \mathrm{~m}^{2} / \mathrm{g}$ to $43 \mathrm{~m}^{2} / \mathrm{g}$, respectively. In intercalation process the interlayer spaces fills with guest ions/anions and surface area of material decrease. Variety of surface area values $270-1550 \mathrm{~m}^{2} / \mathrm{g}$ [11] can be found in literature in close connection with experimental method used for synthesis of graphene materials.

The presence of agglomerated reduced GSS were determined by Raman spectroscopy (Fig. 4) showing G band around $1575-1581 \mathrm{~cm}^{-1}$ and $\mathrm{D}$ band around $1350-1358 \mathrm{~cm}^{-1}$, and 2D at $2702-2732$ that is in a good agreement with literature $[12,13]$. The $\mathrm{D}$ band characterises disorder and number of graphene sheets. By increase of the $\mathrm{D}$ band intensity the number layers and disorder increases [14]. Intercalated $\mathrm{Mg}$ sample shows the shift by $19 \mathrm{~cm}^{-1}$ to lower energies of Raman 2D peak indicating more disordered state comparing with reduced GSS - in literature lower $2 \mathrm{D}$ values $\left(\mathrm{cm}^{-1}\right)$ represent fewer layers of graphene in stacks [15].

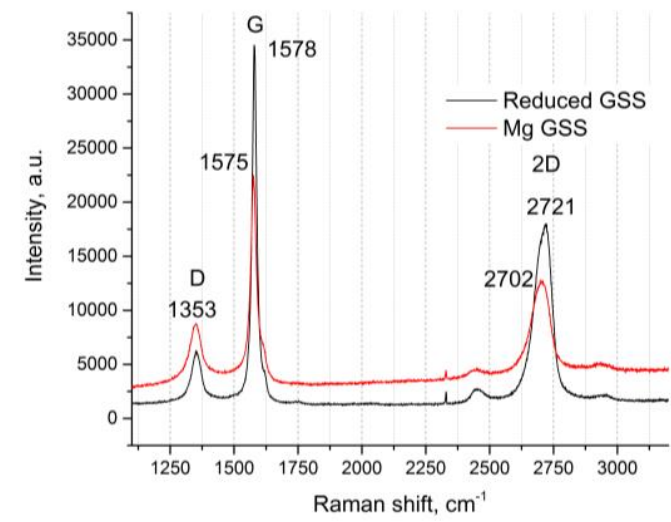

Fig. 4. Raman spectra - reduced GSS and Mg GSS

The amount of desorbed hydrogen was calculated for all samples using volumetric analysis data and shown in the Table 2. The measurements were performed in the temperature range $100-473 \mathrm{~K}$ applying initial hydrogen 
pressure of 2 bar. Mass spectrometry analysis justified that desorbed gas is hydrogen with negligible sulphur additives.

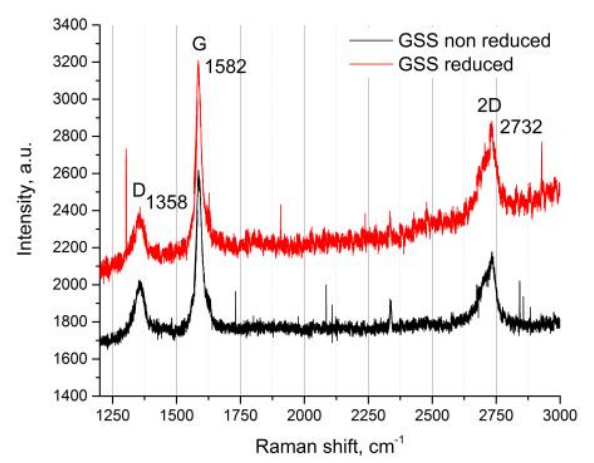

Fig. 5. Raman spectra- reduced GSS and raw-GSS

Table 2. Amount of hydrogen in different measured samples:

\begin{tabular}{|l|c|c|c|}
\hline \multicolumn{1}{|c|}{ GSS } & $\mathrm{H}_{2}$ des $\mathrm{T}, \mathrm{K}$ & Ads $\mathrm{H}_{2} \Delta \mathrm{P}, \mathrm{Pa}$ & $\mathrm{H}_{2}$, wt. $\%$ \\
\hline GSS reduced & -137 & 5000 & $0.12 \%$ \\
\hline Mg GSS nonreduced & -137 & 48000 & $0.14 \%$ \\
\hline GSS nonreduced & -150 & 33000 & $0.43 \%$ \\
\hline
\end{tabular}

\section{CONCLUSIONS}

Few layer graphene multi-sheet stacks are successfully obtained from industrial waste graphite rods using exfoliation method in sulphuric acid solution. $\mathrm{Mg}$ intercalation is performed during exfoliation procedure. Agglomerated samples as well as single sheets of GSS are observed in SEM images. Reduction of samples 'cracks' the material leaving open structures with deep divided stacks. EDS mapping of $\mathrm{Mg}$-intercalated few layer graphene samples shows that $\mathrm{Mg}$ together with other impurity elements are located on the surface of GSS. Heat treatment and degassing of samples doesn't increase material purity. Raman spectroscopy analysis and intense D peak confirms that obtained samples are graphene sheet stacks. Amount of desorbed hydrogen is 0.43 wt.\%, 0.12 wt. $\%, 0.14$ wt.\% for raw GSS, reduced GSS and Mg-intercalated samples, respectively. $\mathrm{Mg}$ intercalation decreased active surface of GSS that caused decrease of amount of adsorbed hydrogen.

\section{Acknowledgments}

Results are partially obtained using infrastructure of Lithuanian Energy Institute with support of COST Action MP1103 "Nanostructured materials for solid-state hydrogen storage". Latvian National Research program IMIS ${ }^{2}$ is greatly acknowledged for financial support.

\section{REFERENCES}

1. Klechikov, A.G., Mercier, G., Merino, P., Blanco, S., Merino, C., Talyzin, A.V. Hydrogen Storage n Bulk GrapheneRelated Materials Microporous and Mesoporous Materials 210 2015: pp. $46-51$. http://dx.doi.org/10.1016/j.micromeso.2015.02.017

2. Patchkovskii, S., Tse, J.S., Yurchenko, S.N., Zhechkov, L., Heine, T., Seifert, G. Graphene NanoStructures as Tunable Storage Media for Molecular HydroGen Proceedings of the National Academy of Sciences of the United States of America
102 2005: pp.

http://dx.doi.org/10.1073/pnas.0501030102

3. Ghosh, A., Subrahmanyam, K.S., Krishna, K.S., Datta, S., Govindaraj, A., Pati, S.K., Rao, C.N.R. Uptake of H 2 and CO 2 by Graphene The Journal of Physical Chemistry C 112 (40) 2008: pp. $15704-15707$.

http://dx.doi.org/10.1021/jp805802w

4. Rao, C.N.R., Maitra, U., Ramakrishna Matte, H.S.S. Graphene: Synthesis, Characterization, and Selected Properties Wiley-VCH Verlag GmbH \& Co. KGaA, Weinheim, 2013: pp. $1-47$.

http://dx.doi.org/10.1002/9783527651122

5. Broom, D.P. Hydrogen Storage Materials - The Characterisation of Their Storage Properties Springer-Verlag London, 2011: pp. $19-59$

6. Ding, F., Yakobson, B.I. Challenges in Hydrogen Adsorptions: from Physisorption to Chemisorption Frontiers of Physics 6 (2) 2011: pp. $142-150$. https://doi.org/10.1007/s11467-011-0171-6

7. Bodrenko, I.V., Avdeenkov, A.V., Bessarabov, D.G., Bibikov, A.V., Nikolaev, A.V., Taran, M.D., Tkalya, E.V. Hydrogen Storage in Aromatic Carbon Ring Based Molecular Materials Decorated with Alkali or Alkali-Earth Metals The Journal of Physical Chemistry C 116 (48) 2012: pp. $25286-25292$. http://dx.doi.org/10.1021/jp305324p

8. Srinivas, G., Guo, Z.X. Graphene-based Materials: Synthesis and Gas Sorption, Storage and Separation Progress in Materials Science 69 2014: pp. 1-60. http://dx.doi.org/10.1016/j.pmatsci.2014.10.004

9. Dresselhaus, M.S., Dresselhaus, G. Intercalation Compounds of Graphite Advances in Physics 51 (1) 2002: pp. $1-186$. http://dx.doi.org/10.1080/00018730110113644

10. Kovtyukhova, N.I., Wang, Y., Berkdemir, A., Cruz Silva, R., Terrones, M., Crespi, V.H., Mallouk, T.E. Non-oxidative Intercalation and Exfoliation of Graphite by Brønsted Acids Nature Chemistry 6 2014: pp. 957-963. http://dx.doi.org/10.1038/nchem.2054

11. Sur, U.K. Graphene : A Rising Star on the Horizon of Materials Science International Journal of Electro-chemistry 2012: pp. 1-12 Article ID 237689. http://dx.doi.org/10.1155/2012/237689

12. Stankovich, S., Dikin, D.A., Piner, R.D., Kohlhaas, K.A., Kleinhammes, A., Jia, Y., Wu, Y., Nguyen, S., Ruoff, R. Synthesis of graphene-Based Nanosheets Via Chemical Reduction of Exfoliated Graphite Oxide Carbon 45 (7) 2007: pp. $1558-1565$. http://dx.doi.org/10.1016/j.carbon.2007.02.034

13. Ferrari, A.C., Basko, D.M. Raman Spectroscopy as a Versatile Tool for Studying the Properties of Graphene Nature Nanotechnology 8 2013: pp 235-246. http://dx.doi.org/10.1038/nnano.2013.46

14. Subrahmanyam, K.S., Vivekchand, S.R.C., Govindaraj, A., Rao, C.N.R. A study of Graphenes Prepared by Different Methods: Characterization, Properties And Solubilization Journal of Materials Chemistry 18 2008: pp. 1517-1523. http://dx.doi.org/10.1039/b716536f

15. Ferrari, A.C., Meyer, J.C., Scardaci, V., Casiraghi, C., Lazzeri, M., $\quad$ Mauri, F., Piscanec, S., Jiang, D., Novoselov, K.S., Roth, S., Geim, A.K. Raman Spectrum of Graphene and Graphene Layers Physical Review Letters 97 (187401) 2006: pp. 1-4. http://dx.doi.org/10.1103/PhysRevLett.97.187401 